\title{
Economia Solidária, bem viver e decrescimento: primeiras aproximações
}

\section{Solidarity Economy, well being and degrowth: preliminary approaches}

\section{Francisco Salau Brasil ${ }^{*}$ Manuela Salau Brasil ${ }^{*}$}

Resumo: Neste artigo, propõe-se apresentar e relacionar os conceitos de economia solidária, bem viver e decrescimento, uma vez que eles estão inscritos no rol das propostas anticapitalistas contemporâneas. Há textos que analisam, isoladamente, cada um deles, destacando o que individualmente concebem sobre os aspectos fundamentais de suas propostas. Originários de países e contextos distintos, têm em comum a ânsia de viabilizar-se como alternativas à forma como a sociedade se organiza atualmente, cada um através de suas particularidades e acentuando determinadas dimensões. Apresentar e discutir suas semelhanças e especificidades é o objetivo deste texto, que pretende em última análise investigar em que medida eles convergem ou podem convergir para uma sociedade melhor.

Palavras-chave: Economia solidária. Bem viver. Decrescimento.

\begin{abstract}
The present paper introduces and establishes a relationship between the concepts of solidarity economy, well being and degrowth as these elements are inscribed on the list of contemporary anti-capitalist proposals. There are texts that present a separate analysis of each element and highlight what they individually conceive with regard to the core aspects of their propositions. The propositions have their origins in distinct countries and settings; what they have in common is their urge to become a feasible alternative to the way society is organised nowadays, although each proposal has particularities and emphasize specific dimensions. The aim of the present paper is to present and discuss these similarities and particularities as well as to investigate to what extent they converge, or could converge to foster a better society.
\end{abstract}

Keywords: Solidarity economy. Well being. Degrowth.

"Mestre em Engenharia Ambiental - Fundação Universidade Regional de Blumenau. Técnico da IESol/UEPG.E-mail: fsbrasil@gmail.com *tDoutora em Sociologia. Assessora da Incubadora de Empreendimentos Solidários (IESOL/UEPG). E-mail: manu_lela2@hotmail.com 


\section{Introdução}

Os debates sobre a crise do capitalismo ensejam vislumbres sobre novas formas de organização da sociedade. Esse exercício tem sua validade não pelo propósito de tentar antecipar o que virá, mas como estratégia para se enxergar e compreender as propostas e experiências que já estão postas e que se orientam por valores e práticas anticapitalistas.

Mais que valores e práticas anticapitalistas, tais propostas e experiências devem estar ancoradas em outra perspectiva de desenvolvimento, que passa obrigatoriamente por refutar o dogma do crescimento a todo custo e o desenvolvimento como variável dependente de uma crescente produção. Problematizar o referido conceito é tarefa que extrapola os limites deste texto, tendo em vista que esta temática sustenta, por si mesma, outros escritos. Resta, portanto, não perder de vista que as três propostas aqui abordadas têm como premissa o questionamento ao que habitualmente se compreende como um desenvolvimento desejável, ou seja, ao desenvolvimento capitalista.

As referidas propostas não esgotam o conjunto das alternativas que se apresentam com a mesma finalidade, mas foram escolhidas por representarem contextos diferentes e acentuarem diferentes aspectos, num convite a possíveis inter-relações entre elas.

Nesse sentido, a opção recaiu sobre a economia solidária, o bem viver e o decrescimento, propostas que, em documento recente, foram mencionadas conjuntamente, ainda que de forma pouco articulada.

A economia solidária, entendida como expressão de uma outra economia, tem aproximação com diversos movimentos sociais que se colocam no mesmo lado da trincheira. A defesa da igualdade, democracia e sustentabilidade, princípios basilares da economia solidária, reúne reivindicações comuns a muitos destes movimentos, embora cada um deles permaneça com sua identidade.

É o caso da recente e ainda tímida associação com o bem viver, conforme ilustrado no documento final da II Conferência Nacional de Economia Solidária, realizada em 2010, um dos pioneiros ao tratar de tal relação.
A economia solidária tem origens remotas na história das sociedades humanas. Ela está intimamente relacionada à luta pela autodeterminação dos povos, ao reconhecimento do conceito de bem-viver e se expressa cotidianamente nas lutas dos povos e comunidades tradicionais contra a mercantilização da vida, em favor dos bens comuns, da gestão comunitária e da reciprocidade. (CONFERÊNCIA NACIONAL DE ECONOMIA SOLIDÁRIA, 2, 2010, p. 10).

O documento não avança sobre a compreensão desse vínculo, que foi reforçado dois anos depois com o texto de orientação da "V Plenária Nacional de Economia Solidária". Neste, a relação entre economia solidária e bem viver é eleita como título da publicação: "Economia solidária: bem viver, cooperação e autogestão para um desenvolvimento justo e sustentável".

No decorrer do mesmo texto, a noção de decrescimento é associada aos outros dois conceitos, embora sem maiores elaborações teóricas, o que impossibilita retirar dele maiores conclusões. O enlaçamento entre eles não é explorado, mas indicado para futuras discussões, o que explica as poucas referências a esses textos.

Com efeito, cada um dos três temas evoca, de forma particular, o desafio de conciliar crítica ao sistema vigente e proposta de uma sociedade diferente, embora o façam sob diferentes perspectivas teóricas e vinculadas a realidades diversas. Tal compreensão não implica entendêlos como teses antagônicas ou inconciliáveis, da mesma forma como não se trata de sobrepô-los ou desconsiderar seus pressupostos e suas referências.

É nessa toada que foi desenvolvido o presente artigo, refletindo sobre os nexos entre economia solidária, bem viver e decrescimento, e sobre as possibilidades daí advindas. Cada um dos conceitos é revisitado nas seções seguintes, para que, ao final, sejam elaboradas reflexões sobre possíveis tramas entre eles, sem pretensões maiores que a de contribuir para um debate recém- inaugurado, relevante e bastante fecundo.

\section{Economia Solidária}

A economia solidária revive e atualiza o movimento cooperativista, reconhecido com 
uma das formas de resistência dos trabalhadores frente ao capitalismo do século XIX. Esse movimento foi protagonizado pelos socialistas utópicos, os quais alimentaram com suas ideias e intervenções práticas um rol de experiências que foram exitosas por um considerável período.

No Brasil, a economia solidária renasce no contexto de crise dos anos 1980, crise que tem sua face mais evidente com o aumento do desemprego e suas consequências perversas. Se esse é um fator impulsionador do retorno de tais experiências, não se pode autorizar a hipótese de que a economia solidária serve apenas a tal propósito. Sua virtude não reside em acomodar o crescente número de excluídos, mas em almejar um sistema que não seja produtor de exclusão.

É importante lembrar que o setor informal era o destino preferencial - talvez o único - para essa população, e que nele não há qualquer ímpeto de confrontação ao sistema; ao contrário, há uma replicação da mesma lógica do grande capital. Ora, não foi o setor informal o destino de todos os desempregados e trabalhadores precários, pois parte deles ingressou em empreendimentos econômicos solidários como forma de garantir trabalho e renda.

Deve-se apreciar a hipótese de que o desemprego não explica sozinho as motivações para o reaparecimento da economia solidária, como bem observou Gaiger (2004, p. 376):

[...] embora o desemprego ou a perspectiva do desemprego apareçam como forças impulsionadoras do cooperativismo de trabalho na última década, dificilmente podem ser a única variável. Em outras épocas, o desemprego não engendrou cooperativas, ao menos na quantidade agora observada.

$\mathrm{Na}$ visão do autor, não apenas as mudanças mais gerais da sociedade levaram ao aumento do número de empreendimentos econômicos solidários, mas os resultados de diversas pesquisas empíricas forneceram elementos para compreender os aspectos mais próximos das experiências que contribuíram para a aludida expansão (GAIGER, 2004).

Nesse sentido, o referido autor enumera os seguintes fatores, que juntos conformam o referido crescimento: a) existência de grupos com experiência anterior em práticas que evocam o associativismo; b) presença de organizações e li- deranças que representam de forma autêntica os interesses dos grupos e que fazem a articulação com outros agentes; c) a gênese dos empreendimentos econômicos solidários, em sua maioria, está na economia popular, apesar de que aquela “... representa outra economia, antagônica ao caráter e ao lugar histórico subalternos que ambas [economia capitalista e economia popular], por razões diversas, reservem a quem vive do trabalho." (GAIGER, 2004, p. 375).

O autor elenca ainda outros fatores: d) atuação de instituições para sensibilização e apoio ao trabalho associado; e) o aumento do desemprego, que, conjugado com os demais aspectos, vitalizou a economia solidária a despeito das alternativas habituais de trabalho precário e clandestino, geralmente acionadas nessas conjunturas; g) reconhecimento da economia solidária no plano político e ideológico (GAIGER, 2004).

A história de cada grupo e de seus trabaIhadores, seu grau de envolvimento em lutas sociais, são fatores propulsores para o ingresso na economia solidária, tendo um peso maior se comparado com o impacto da crise do trabalho ou outros aspectos estruturais.

A essa herança de lutas populares somou-se o apoio de segmentos da igreja católica, organizações não governamentais e universidades, formando uma rede que se entendeu até as esferas governamentais. Durante a edição do Fórum Social Mundial de 2003 foi anunciada a criação da Secretaria Nacional de Economia Solidária - SENAES, como compromisso assumido pelo presidente eleito e fazendo-se cumprir uma demanda do movimento social da economia solidária.

A criação da SENAES como parte do Ministério do Trabalho e Emprego garantiu um novo estatuto à economia solidária, que tem sido incorporada a diversas estruturas municipais e estaduais. No mesmo ano constituiu-se o Fórum Brasileiro de Economia Solidária- FBES, que se ramificou em fóruns estaduais, regionais e municipais, congregando trabalhadores e trabalhadoras dos empreendimentos de economia solidária, as assessorias de apoio (incubadoras universitárias, entre outros) e os gestores públicos.

A relação entre SENAES e FBES é assim descrita por Singer: "A Senaes entende que sua missão é difundir e fomentar a economia solidária em todo o Brasil, dando apoio político e material 
às iniciativas do Fórum Brasileiro de Economia Solidária." (SINGER, 2004, p. 4).

Na página da SENAES pode-se ler sobre a economia solidária:

a economia solidária aponta para uma nova lógica de desenvolvimento sustentável com geração de trabalho e distribuição de renda, mediante um crescimento econômico com proteção dos ecossistemas. Seus resultados econômicos, políticos e culturais são compartilhados pelos participantes, sem distinção de gênero, idade e raça. Implica na reversão da lógica capitalista ao se opor à exploração do trabalho e dos recursos naturais, considerando o ser humano na sua integralidade como sujeito e finalidade da atividade econômica. (BRASIL, 2012).

Na Carta de Princípios da Economia Solidária está claro seu papel de proporcionar, no curtíssimo prazo, uma alternativa de sobrevivência aos trabalhadores e trabalhadoras, mas também de propor, num horizonte maior de tempo, uma mudança mais profunda: "São práticas fundadas em relações de colaboração solidária, inspiradas por valores culturais que colocam o ser humano como sujeito e finalidade da atividade econômica, em vez da acumulação privada de riqueza em geral e de capital em particular." (CARTA DE PRINCÍPIOS DA ECONOMIA SOLIDÁRIA, 2010, p. 1).

Em sintonia com esse princípio, a carta salienta que "a economia solidária não está orientada para mitigar os problemas sociais gerados pela globalização neoliberal" (CARTA DE PRINCÍPIOS DA ECONOMIA SOLIDÁRIA, 2010, p. 3), opondo-se, portanto, ao discurso de funcionalidade ao sistema excludente.

Apontando para uma sociedade contrária ao capitalismo e para outra forma de desenvolvimento, aqui mencionado o sustentável ${ }^{1}$, a economia solidária se materializa essencialmente nos empreendimentos econômicos solidários.

Fazem parte desse conjunto as cooperativas, associações, clubes de troca - com ou sem o uso de moeda social -, empresas recuperadas (oriundas de fábricas falidas), feiras, grupos informais, entre outros.

\footnotetext{
${ }^{1}$ A noção de desenvolvimento sustentável é, a nosso juízo, incompatível com uma proposta de desenvolvimento solidário.
}

Independentemente de sua constituição jurídica, esses empreendimentos orientam-se por quatro princípios, herdeiros do movimento cooperativista: cooperação ao invés da competição; autogestão ao invés de heterogestão; solidariedade no lugar de individualismo e centralidade no ser humano e não no capital.

Todos eles representam importantes desafios, sendo que a autogestão é a ponta mais visível dessas potenciais mudanças. É a partir dela que os trabalhadores vivenciam uma nova cultura do trabalho, ajudando a tecer outras relações para além do empreendimento. A autogestão é exercitada no cotidiano dos empreendimentos; é dela que depende a possibilidade de conjugar-se economia e solidariedade na gestão de empreendimentos coletivos.

Mesmo que motivada, prioritariamente, pela garantia de sobrevivência, ao longo do tempo a economia solidária vem abrigando adesões que avançam sobre essa condição. Há várias pesquisas que mostram, ao lado das dificuldades e limites dos empreendimentos econômicos solidários, as virtuosidades que essas experiências propiciam àqueles que dela participam e que a constroem na prática. Os resultados são lentos, por suposto, mas englobam desde questões objetivas até as subjetivas - aliás, estas últimas com maior força.

Os sucessos da economia solidária alavancam incursões mais audaciosas, o que inclui uma plataforma de mudanças de maior alcance, que visam ao conjunto da sociedade e não se restringem aos empreendimentos ou mesmo ao interior do movimento da economia solidária. Daí seu lugar enquanto prática e proposta anticapitalista, congregando um esforço que ultrapassa os limites da esfera econômica para contemplar as demais dimensões da vida humana.

Há que se considerar os diferentes tempos e os avanços desiguais produzidos em torno de cada dimensão, o que revela, no fundo, o grau de prioridade que cada uma assume nas propostas às quais estão relacionadas. Nota-se, por exemplo, que a questão ambiental, embora esteja presente como uma dimensão da economia solidária, é menos proeminente quando comparada ao que propugnam os defensores do bem viver e decrescimento.

Quanto ao tema do desenvolvimento, indispensável para qualquer alternativa crítica, não há muita evolução no caminho para se construir 
um modelo de desenvolvimento solidário. Esse vácuo não esconde o conflito entre um modelo hegemônico, sancionado e estimulado através das políticas adotadas pelo governo federal, em contraste com o que está sendo gestado na SENAES, órgão do mesmo governo, mas que encarna uma filosofia que confronta a anterior. Há, portanto, um descompasso também entre a economia solidária enquanto perspectiva teórica e a economia solidária como prática concreta, pois dependem de condições distintas para se efetivarem.

Se a economia solidária ressurge na década de 1980 e ganha maior visibilidade na década seguinte, como resultante de processos históricos maturados e, em certa medida, precipitados pelo aumento do desemprego, hoje o cenário é outro. A economia brasileira se recuperou, e a geração de emprego formal é um dos símbolos do crescimento econômico. O impacto para o número de empreendimentos e de trabalhadores e trabalhadoras da economia solidária ainda não é conhecido e, quando for apurado, servirá para realçar com maior nitidez o peso dos fatores de adesão e fidelidade ao trabalho associado.

O que está em jogo é sua capacidade de confirmar-se como um projeto que suplanta o objetivo de gerar trabalho e renda, e cuja evolução é resultado das práticas exitosas e das conquistas em um plano maior. Há várias lutas sendo travadas nesse sentido, e em meio das quais os empreendimentos, também representados naquelas instâncias, resistem mesmo que em condições adversas. O desfecho desses embates pode fomentar ciclos de expansão ou retração da economia solidária, contribuindo para analisar seu potencial diante da luta anticapitalista e seus possíveis enlaces com outras propostas.

\section{Bem Viver}

Os conceitos indígenas Sumak Kawsay (quéchua equatoriano) e Suma Qamaña (aimará boliviano) são traduzidos como Bem Viver ou Viver Bem² (Buen Vivir ou Vivir Bien). De acordo

\footnotetext{
${ }^{2}$ A melhor tradução para Sumak Kawsay (ou Teko Porá), de acordo com Regazzoni (2010), é o de Vida Boa. Para Arkonada (2010) a tradução escolhida é Vida em Plenitude: "Em aimará, Suma é traduzido como algo muito bom, excelente, plenitude. E Qamaña como conviver, viver em definitivo, de modo que o termo Suma Qamaña poderia ser traduzido mais aproximadamente como 'vida em plenitude', e uma tradução similar pode ser feita do termo quéchua Sumak Kawsay." (ARKONADA, 2010, p. 11).
}

com Susana Merino (2013), a melhor tradução seria "bem conviver", tendo em vista que se trata de uma condição que só faz sentido se envolver todas as pessoas.

Como a economia solidária, trata-se de um projeto anticapitalista, que na visão de León $\mathrm{T}$. tem a seguinte configuração:

El Buen Vivir articula un acervo de visiones y prácticas presentes en nuestra historia y en nuestra realidad contemporánea y que por tanto son el sustento concreto de las alternativas. El Buen Vivir no es sólo una utopía hacia futuro, sino que nombra también porciones de nuestra realidad; hay en el aquí y ahora, en nuestro día a día, por así decir pedacitos de Buen Vivir que hacen viable esta propuesta. (LEÓN, 2010, p. 24).

Tal proposição contemplaria, na visão da autora, demandas dos povos ancestrais, dos movimentos feministas e ecológicos, que ganhariam do ponto de vista econômico uma arquitetura desenhada com vistas a uma "economía para la vida".

É importante frisar a complexidade dessa proposta, que não deve ser reduzida quanto à sua origem e seu alcance. Nas palavras de Acosta:

[...] hay que aceptar que lavisión andina no es la única fuente de inspiración para impulsionar elBuenVivir. Incluso desde círculos de la cultura occidental se hanlevatado y ya desde tiempo atrás muchas vocês que podrían estar de algunamaneraen sintonia com esta visión indígena y viceversa. El concepto delBuenVivir no solo tiene um anclaje histórico enel mundo indígena, se sustenta también em algunos princípios filosóficos universales: ari stotélicos,marxistas,ecológicos, feministas, cooperativistas, humanistas [...] (ACOSTA, 2010b, p. 13).

Sem negar o legado dos povos indígenas, essa concepção não está presa a uma determinada população ou época. É um paradigma composto pelas dimensões social, econômica, cultural e religiosa-transcendental que se fundem em um sistema que preza pela solidariedade, convivência, reciprocidade e qualidade de vida em que a comunidade e a natureza vivem harmonicamente (REGAZZONI, 2010).

A noção de qualidade de vida advinda do bem viver não deve ser confundida com a de 
bem-estar, pois nesta última a possibilidade de viver melhor só é permitida quando o outro passa a viver pior, seguindo a lógica individualista e excludente que impera na racionalidade capitalista. Ao contrário, o bem viver se pauta na valorização da vida em comunidade e no reconhecimento da natureza como sujeito de direitos, e não como recurso utilizado para gerar lucro (RAUBER, 2010; AVENDAÑO, 2010; CÉSPEDES, 2010; ARKONADA, 2010).

Ainda com o intuito de marcar a diferença e a oposição entre aqueles dois conceitos, nos valemos do que escreveu Arkonada:

O paradigma do Viver Bem ensina-nos não a viver melhor, mas sim a viver bem com menos. Ele precisa ser um marco na educação. Precisamos criar uma ética de Viver Bem e reconstruir um pensamento e uma forma de vida mais comunitária, com outras formas de repensar as relações interpessoais e a economia, um equilíbrio entre a cultura da Mãe Terra, em que complementaridade ou a reciprocidade sejam as duas faces de uma mesma moeda. (ARKONADA, 2010, p. 13).

Viver com menos é também um dos princípios basilares do decrescimento, além de se coadunar com o projeto da economia solidária, embora nesta última esse aspecto não seja, até então, motivo de destaque. Os valores e princípios dessas concepções não são antagônicos, mas refletem ângulos diversos de uma mesma perspectiva.

Quanto aos valores sobre os quais está assentado o bem viver, Acosta (2010a, p. 24) confirma:

Las equidades, tanto como la igualdad y la libertad, así como la justicia social [productiva y distributiva], tanto como la ambiental están en la base del Buen Vivir [sumak kausay]. Las equidades, basadas en la búsqueda de la 'igualdad sustantiva' [István Mészáros], entonces, tendrían que venir como resultado de un proceso que reduzca dinámica y solidariamente las desigualdades e inequidades existentes.

Com tantos pontos em comum entre economia solidária e bem viver, é importante salientarmos algumas das especificidades entre elas. O bem viver é constitucionalmente reconhecido na Bolívia (2009) e no Equador (2008).
Entendendo a Constituição como um "projeto político de uma vida em comum" (ACOSTA, 2010b, p. 5), o Equador contemplou mudanças estruturais em sua sociedade, inscritas na Constituição de Montecristi. São 99 artigos destinados ao bem viver, de um total de 444, que expressam um conjunto de direitos que estão em mesmo grau de importância que os demais.

Acosta comemora outro aspecto original dessa Constituição, a conversão da natureza em sujeito de direitos (ACOSTA, 2010b).

La Naturaleza vale por símisma, independientemente de lautilidad o usos del ser humano...Estos derechos defienden mantener los sistemas de vida, los conjuntos de vida. Su atención se fija em los ecosistemas, em las colectividades, no em los indivíduos. (ACOSTA, 2010b, p. 20).

\section{O autor complementa:}

Dotarle de Derechos a la Naturaleza significa, entonces, alentar politicamente su paso de objeto a sujeto, como parte de un proceso centenário de ampliación de los sujetos del derechos.... Lo central de los Derechos de la Naturaleza es rescatar el 'derecho a la existência' de los propios seres humanos... La liberación de la Naturaleza de esta condición de sujeto sin derechos o de simple objeto de propiedad, exige un esfuerzo político que le reconozca como sujeto de derechos. Y esta lucha de liberación empieza por reconocer que el sistema capitalista terminará por destruir las condiciones biofísicas de existencia. (ACOSTA, 2010b, p. 18).

O posicionamento a favor da natureza e da impossibilidade de seus direitos serem preservados no sistema capitalista e a inclusão dessas questões na Constituição são marcas distintivas do contexto daquele país.

No Brasil, a economia solidária ainda está na batalha por um marco jurídico próprio, e mesmo que a política da SENAES tenha conseguido construir parcerias com outras políticas públicas, elas são todas feitas com setores que compartilham certo distanciamento do núcleo duro da administração federal. Formam-se espécies de redes que agregam experiências de políticas públicas ditas alternativas, que contam com muita disposição e militância, mas com poucos 
recursos financeiros e incentivos governamentais. Contrastando com o modelo do Equador, no Brasil sequer o Estatuto de Ministério, requerido pelo movimento da economia solidária, foi incorporado pela atual administração federal.

Tanto em um caso como no outro, há uma disputa quanto ao modelo de desenvolvimento adotado pelo governo e acolhido pela sociedade, mas na realidade brasileira essa questão nos parece bem menos avançada.

Pensando no Brasil, indagamos até que ponto é possível o mesmo governo apoiar e incentivar dois tipos antagônicos de desenvolvimento. Embora as discussões colocadas de forma dicotômica percam em qualidade, este parece ser um caso em que a exceção é válida. Por exemplo, os mesmos instrumentos de política macroeconômica que são acionados para atingir objetivos da agenda do desenvolvimento capitalista - hoje praticamente voltados para o crescimento econômico, a contenção da inflação e o controle cambial - são indiferentes ou incompatíveis com o desenvolvimento proposto pela economia solidária.

Harmonizar esses resultados é inviável, e a reversão desse quadro depende de uma opção política, ou melhor, de uma pressão política em nome de um projeto político, lição que pode ser aprendida com os países vizinhos.

É notável que o bem viver representa outra forma de desenvolvimento, contrário ao capitalista e ao dito sustentável, e que a natureza tem um outro papel nesse processo. Natureza e ser humano protagonizam esse sistema, ao invés do capital. E essa visão é anunciada e enfatizada, conforme se pode ler nas palavras de Gudynas e Acosta (2013) quando afirmam que o bem viver parte

de uma visão que supere as estreitas margens quantitativas do economicismo e permita a aplicação de um novo paradigma cujo fim não sejam os processos de acumulação material, mecanicista e interminável de bens, mas que promova uma estratégia econômica inclusiva, sustentável e democrática. (GUDYNAS; ACOSTA, apud MERINO, 2013, p. 3).

A economia solidária, ao se colocar como um modelo alternativo de desenvolvimento e de sociedade, o faz com um tom menos ousado e contundente. Em alguns textos, a exemplo do mencionado no início deste trabalho, o desenvolvimento sustentável surge como ilustração da forma de desenvolvimento compatível ou desejável, o que não corresponde a uma visão compatível com um desenvolvimento solidário de fato. A amplitude dessa questão excede o espaço deste texto, mas trata-se de um aspecto que não pode ser negligenciado ou postergado em demasia.

De igual forma, o debate conceitual sobre economia solidária e bem viver deve ser cada vez mais aprofundado, tratado de forma sistemática em diferentes arenas e pautado nos fóruns, empreendimentos e espaços de formações. É necessário localizar as convergências e ressaltar as nuances entre essas concepções, assim como de outras que podem se colocar como matrizes de resistência e alternativa ao capitalismo.

Ambas as propostas adotam princípios que valorizam novas formas de relacionamento entre os seres humanos e entre eles e a natureza, baseadas na solidariedade e reciprocidade. Ambas se comprometem com formas coletivas de trabalho e com a retirada da centralidade do capital, destinando papel importante para a dimensão política de suas propostas.

Tanto uma quanto a outra tem o desafio de desvincular-se da ideia de que representam grupos específicos da população - os indígenas no caso do bem viver e os desempregados e pobres, a economia solidária -, o que enfraqueceria seu potencial na luta anticapitalista.

Tentando promover a união entre esses caminhos, Acosta (2010a, p. 20-1) defende que

El valor básico de la economía, en un régimen de Buen Vivir, es la solidariedad. Por lo tanto se busca una economía distinta a la actual, caracterizada por la búsqueda de la libre competencia, que anima al canibalismo económico entre seres humanos y que alimenta la especulación financiera. A partir de la definición constitucional de una economía social y solidaria se aspira a construir relaciones de producción, de intercambio y de cooperación que propicien la suficiencia [más que la sola eficiencia] y la calidad, sustentadas en la solidaridad.

Ao mesmo tempo, é notório o empenho do movimento da economía solidária em conhecer e reconhecer as afinidades com o bem viver, 
conforme evidenciado nos mencionados textos orientadores de debates em importantes eventos e fóruns.

A sociedade frugal preconizada pelo decrescimento não destoa de tais proposições; ao contrário, alia-se a eles mesmo que de forma ainda pouco visível.

\section{Decrescimento}

O termo decrescimento pode causar desconforto ou desconfiança mesmo para aqueles acostumados com um vocabulário contestador. Em especial, porque o foco do atual modelo de desenvolvimento é o crescimento ininterrupto da economia, e o termo em questão parece acrescentar elementos negativos a essa qualidade. Os anúncios nos jornais (dos mais diversos meios) tratam índices de crescimento baixos, ou relativamente baixos, como uma terrível notícia, antecipando consequências nefastas para a economia e sua população.

Vivemos numa sociedade do crescimento. Assim, qualquer resultado da economia que não indique tal condição é motivo de preocupação. Não obstante, decrescimento não quer dizer crescimento econômico negativo. Trata-se de negar o crescimento como principal meta a ser atingida. Essa nova forma de pensar, ao ser levada à prática, pode implicar uma variação abaixo de zero do Produto Interno Bruto. Porém, isso não acontecerá necessariamente em todas as cidades, estados ou países.

Segundo Flipo (2008), a palavra decrescimento foi utilizada pela primeira vez na tradução de um artigo de Nicholas Georgescu-Roegen cujo título era "The Entropy Law and The Economic Process" (A Lei da Entropia e o Processo Econômico). Apesar de conseguir alguns espaços e simpatizantes, sobretudo nas correntes de esquerda, o decrescimento tem muito a percorrer para se tornar mais difundido.

Além de soar como uma pura e simples defesa de crescimento negativo - argumento indefensável dentro de uma sociedade de crescimento, Latouche (2012) elenca outros motivos que dificultam a popularização ou mesmo aceitação do termo. O autor afirma que decrescimento não é um conceito, mas um slogan provocador que nota a necessidade de uma ruptura com a sociedade do crescimento. O termo tem um caráter negativista, o que também é imperdoável em uma sociedade onde tudo tem que ser "positivado". Por fim, Latouche (2012, p. 45) atesta: "em suma, o decrescimento não é sexy".

Entretanto, algumas dessas barreiras têm o seu lado positivo. Por ser um termo desafiador e provocador, ele tende a chocar as pessoas mais do que outras expressões que são também antagônicas ao capitalismo. E esse choque pode levar a reflexões/questionamentos sobre um dos pilares do capitalismo: o crescimento econômico.

A excentricidade da palavra pode causar a falsa impressão de que se trata de uma variação negativa do PIB, mas em compensação pode blindar o conceito de apropriações, pelo repertório capitalista. Um exemplo de expressão que foi apropriada é desenvolvimento sustentável (embora a moda da vez pareça ser economia verde), utilizada para maquiar o capitalismo de forma a deixá-lo como se fosse ambientalmente sustentável.

Se o termo decrescimento só ganhou maior notoriedade neste século, especialmente na França, o debate acerca de um limite para a economia já vem de mais tempo. Na década de 1970, o Clube de Roma se reuniu e lançou o documento "Limites do Crescimento". Tal iniciativa defendia o crescimento zero, pois se entendeu (já naquela época) que as atividades econômicas possuem um limite: o limite da natureza.

Merico (2002) resume a importância da natureza na manutenção da vida humana em três funções. A primeira delas está no fornecimento de matéria-prima para a fabricação dos mais diversos bens.

A segunda é a absorção de resíduos. Eventualmente, tudo o que é produzido pela ação humana é despejado na natureza, seja no ar, solo ou água. A natureza tem uma capacidade de absorção de modo a manter o planeta em um certo estado de equilíbrio. Tal capacidade é também conhecida como resiliência, um termo físico que tem como conceito a capacidade de um objeto sofrer pressão e conseguir retornar ao seu estado normal.

Por fim, há a provisão de serviços ambientais. Entre tais serviços, estão a regulação climática e manutenção dos ciclos biogeoquímicos, que garantem fornecimento de elementos químicos na natureza, tais como água, carbono, oxigênio, enxofre e nitrogênio.

Esses serviços são diretamente afetados quando a capacidade de absorção de resíduos 
da natureza é ultrapassada, bem como pela exploração indevida de recursos naturais. Ou seja, o crescimento contínuo da economia pode comprometer seriamente essas funções, que são essenciais para a vida humana.

Essa preocupação com a sustentabilidade ambiental, sobretudo quando considerado que o conceito de desenvolvimento sustentável ${ }^{3}$ já é amplamente conhecido há mais de 20 anos - e apesar disso ainda tomamos um rumo contrário ao da sustentabilidade - motivou o surgimento do decrescimento.

Para Flipo (2008), o decrescimento, apesar de ainda não possuir um conceito unificado ou definido, pode ser caracterizado como a junção de cinco diferentes fontes. Enquanto duas destas podem ser ligadas às questões ambientais (sustentabilidade ecossistêmica e bioeconomia), as outras fontes têm origem na questão cultural, democracia e a crise da sociedade industrial. Dentre as diversas fontes que o decrescimento possui, Garcia (2012) aponta que é a crise ecológica a principal crítica feita ao atual modelo de desenvolvimento.

Latouche (2009a, 2009b, 2012), principal teórico do decrescimento, o descreve como uma matriz de alternativas. Nesse sentido, MartínezAlier et al. (2010) se refere ao decrescimento como uma palavra-bomba e Kallis (2011) o considera como uma palavra-chave, uma ideia guarda-chuva, que tem a visão de uma sociedade com um metabolismo mais estável, onde o bemestar decorre da igualdade e simplicidade e não da riqueza material.

Para Martínez-Alier et al., (2010) o pensamento do decrescimento é centrado na questão de como se pode desfrutar de uma boa vida. Leff (2008) defende o decrescimento como a tomada de consciência sobre um processo que se instaurou dentro da civilização que joga contra a vida do próprio planeta tanto quanto a qualidade de vida do ser humano.

A declaração final do primeiro Congresso Internacional sobre Decrescimento para Sustentabilidade Ecológica e Igualdade Social (evento realizado em 2008, Paris) traz algumas considerações sobre decrescimento. Conforme esse documento, o decrescimento é

\footnotetext{
${ }^{3}$ Novamente remete-se às críticas direcionadas à noção de desenvolvimento sustentável.
}

caracterizado, entre outras coisas, pela ênfase na qualidade de vida, ao invés da quantidade de consumo; satisfação das necessidades básicas humanas para todos; redução substancial da dependência das atividades econômicas e aumento do tempo livre, atividades não remuneradas, senso de comunidade; princípios de igualdade, participação democrática, diversidade, respeito aos direitos humanos e a diferenças culturais. (INTERNATIONAL CONFERENCE ON ECONOMIC DE-GROWTH FOR ECOLOGICAL SUSTAINABILITY AND SOCIAL EQUITY, 2008).

O fato de não haver um conceito definido ou conhecido pode ser, num primeiro momento, algo prejudicial para a disseminação dos ideais do decrescimento. Não obstante, tal fato não impediu que a economia solidária - outro movimento anticapitalista - pudesse avançar. Alguns dos princípios e características decrescentistas, sobretudo aqueles que se referem à qualidade de vida e à satisfação das necessidades humanas, remetem ao movimento do bem viver.

Já determinados pontos levantados na declaração final de 2008 apresentam alguns elementos em consonância com a economia solidária. Além dessas três alternativas elencadas, certamente há fatores que aproximam o decrescimento de outras propostas de desenvolvimento. Como esse não é o foco deste trabalho, avança-se o debate.

Como dito anteriormente, o termo decrescimento pode dar a falsa noção de uma defesa do crescimento negativo. Não sendo esse o caso, Latouche (2009a, 2009b) escreve que seria mais conveniente a utilização do termo acrescimento, da mesma forma que existe o ateísmo, até porque o crescimento é percebido como uma religião, uma questão de fé. Assim, o autor reforça o propósito de abandonar a sociedade do crescimento, "cujo motor não é outro senão a busca do lucro por parte dos detentores do capital, com consequências desastrosas para o meio ambiente e portanto para a humanidade." (LATOUCHE, 2009a).

O que diferencia o decrescimento das duas propostas anteriores é a sua crítica mais contundente (já observada até mesmo na sua nomenclatura) em relação à importância que é dada ao crescimento da economia. Nesse sentido, Latouche (2012, p. 46) afirma que 
Romper com la sociedad de crecimiento, no es preconizar outro crecimiento, ni tampoco outra economia, sino salir del crecimiento y del desarrollo y, por ló tanto, de la economia, es decir, del imperialismo de la economia, para recuperar ló social y ló político.

Nessa toada, Martínez-Alier et al. (2010) ponderam se devemos sair da economia ou do economicismo. Corroborando esse argumento, é preciso fazer a distinção entre economia, que se origina do grego (oikos = casa) e significa administrar a casa, daquilo que Aristóteles denomina de crematística (do grego khrema = riqueza). Economia pode ser definida como

a ciência social que estuda como o indivíduo e a sociedade decidem utilizar recursos produtivos escassos, na produção de bens e serviços, de modo a distribuí-los entre as várias pessoas e grupos da sociedade, com a finalidade de satisfazer às necessidades humanas. (VASCONCELLOS, 2000, p. 21).

Já o conceito de crematística foi utilizado por Aristóteles para definir a produção com fins de obter lucro. Assim, o filósofo grego fazia a distinção entre esse tipo de produção daquele que tem como fim a satisfação das necessidades - esta sim, denominada economia (FOLADORI, 2001; PENGUE, 2009).

Considerando essa distinção, tanto o decrescimento quanto a economia solidária e o bem viver comungam da rejeição ao economicismo, da noção de economia como instrumento de acumular riqueza, ou seja, a crematística.

Outro ponto em comum entre decrescimento e economia solidária é o uso de moeda social como forma de fortalecer a economia local e os empreendimentos solidários. A relocalização é uma das propostas do decrescimento, e nela consiste a pluridade de moedas, mantendo o fluxo econômico dentro da região e, conforme Latouche (2012), tais moedas não poderiam ser utilizadas para fins especulativos. Em ambas as propostas, portanto, a moeda adquire funções distintas daquelas conferidas pelo sistema atual.

O decrescimento é uma forma de contestação a um dos princípios basilares do capitalismo, portanto, supõe sua substituição. Concorda-se com Martínez-Alier et al. (2010), quando se aborda a importância do decrescimento caminhar ao lado de movimentos sociais tanto do norte quanto do sul. Decrescimento, bem viver e economia solidária são projetos que ressaltam questões diferentes, mas não são propostas antagônicas. Suas semelhanças devem ser apontadas e, acima de tudo, há que se fazer um diálogo a favor de suas convergências e complementariedades.

\section{Considerações Finais}

As três propostas em tela partem de uma crítica à noção do desenvolvimento capitalista. Mesmo nas correntes de pensamento menos conservadoras, o desenvolvimento é visto como dependente da produção e da economia, ou seja, tudo o mais está a reboque de um tal funcionamento da economia que permita e acelere os níveis de expansão econômica. Na contramão dessa racionalidade, a economia solidária, o bem conviver e o decrescimento produzem outras lógicas em que o desenvolvimento é, no mínimo, ressignificado.

Embora esteja na raiz das propostas indicadas, esse debate não vem sendo realizado de forma homogênea, tampouco produz unanimidade em suas proposições. Além do mais, são informados por perspectivas teóricas e realidades concretas distintas, embora permaneçam unidas pela premissa de rejeição ao sistema posto. De qualquer forma, o debate está recém-inaugurado, e urge debruçar-se sobre ele.

Conforme advertido inicialmente, o texto orientador para a $\mathrm{V}$ Plenária Nacional de Economia Solidária manifesta, sem problematizar, os elos entre economia solidária, bem viver e decrescimento. Fazemos essa ressalva para justificar as poucas menções a ele, que serviu de base para extrapolarmos nossas reflexões. Aliás, um dos desafios é proporcionar amplo conhecimento e popularização - sem redundar em banalizações - de tais alternativas.

De fato, cada uma das três propostas contém elementos que podem ser melhor compreendidos quando cotejados com os demais. A necessidade e urgência de tal exercício não reside apenas no refinamento de construções teóricas, mas na percepção das condições práticas para que se revertam as crescentes consequências negativas do capitalismo.

As nuances entre elas não devem ser minimizadas, tampouco devem inviabilizar alianças mais fortes - que devem ser tecidas no plano teórico e prático -, tendo em vista que se trata, 
não de antagonismos, mas sim de ênfase em determinados aspectos. No bem viver a defesa da natureza é mais radical, e o cuidado com a Mãe Terra (Pachamama) é uma das principais reivindicações, acompanhada de uma crítica contundente em relação aos conceitos de crescimento e desenvolvimento (incluindo o desenvolvimento sustentável, que ainda figura como uma bandeira na maioria das discussões sobre a economia solidária). Também a importância da dimensão espiritual nos parece mais significativa nessa proposta, em consonância com a tradição da qual se originou.

A crítica ao desenvolvimento e crescimento é a pedra angular do decrescimento, embora não esteja ancorada em modos de vida ancestrais, como o anterior, e não projete princípios para novos formatos organizativos e de trabalho, como a economia solidária.

Por sua vez, a economia solidária não tem apresentado de forma tão clara e intensa sua recusa ao formato de desenvolvimento capitalista, embora seja um pressuposto de sua teoria. Ao mesmo tempo, é a autogestão sua força motriz, amparada pelo grande número de experiências que tem ajudado a construir um repertório que permite avaliar suas conquistas e suas deficiências, que podem ser confrontadas ou complementadas com as duas outras propostas aqui evidenciadas.

Enxergar essas particularidades não nos demove da ideia de que os vínculos entre elas devem ser fortalecidos. Essa articulação é mais facilmente construída naquilo que é seu elo de maior integração, ou seja, como estratégias de resistência, tornando-se mais complexa quando diz respeito à elaboração e defesa de uma alternativa concreta e viável. Não está em jogo a preferência por uma em detrimento das demais, não é essa a estratégia requerida para o enfrentamento proposto. Da mesma forma, há que se aparar possíveis discordâncias teóricas a fim de não torná-las justificativas que inviabilizem o diálogo e o aprendizado que elas permitem.

A articulação entre economia solidária e bem viver está mais avançada, e as duas denominações começam a surgir de forma mais frequente nos mesmos textos. Em 2013, por exemplo, o Fórum Brasileiro de Economia Solidária criou a campanha "Envolva-se para o bem-viver", num chamado para a "construção de uma sociedade solidária e pelo bem-viver"
(CIRANDAS, 2013). De fato, parece inviável apartar os dois conceitos, e talvez o próximo desafio seja aproximá-los do decrescimento.

Apropriar-se desse debate e aprofundar-se nele é condição sinequa non para validar uma proposta com suporte e legitimidade requeridos para a luta por uma nova forma de organização societal. Enxergar confluências e trabalhar em nome delas é um exercício inescapável para aqueles imbuídos do desejo de fazer aumentar as chances de um futuro melhor.

Uma das maiores cobranças que se faz a essas e outras alternativas é sobre sua capacidade de consolidar um contra-ataque eficiente ao capitalismo, produzindo uma revolução civilizatória. Essa expectativa não pode ser respondida no tempo presente, mas nele é preparada a terra e são plantadas as sementes do que pode vir a florescer no futuro.

\section{Referências}

ACOSTA, A. El buen (con) vivir, una utopía por (re) construir: alcances de la constitución de Montecristi. Outra Economía, Buenos Aires, v. IV, n. 6, p. 8-31, 2010a. Disponível em: <http://www.riless.org/ otraeconomia/acosta6.pdf>. Acesso em: 10 dez. 2011.

El Buen Vivir en el camino del pos-desarrolllo. Uma lectura desde la Constitución de Montecristi. Policy Paper 9, Equador, oct. 2010b.

ARKONADA, K. Descolonização e Viver Bem são intrinsecamente ligados. IHU On-Line, São Leopoldo, ed. 340, p. 10-13, 2010. Disponível em: <http://www. ihuonline.unisinos.br/index.php?option=com_conten $\mathrm{t} \&$ view $=$ article\&id $=3439 \&$ secao $=340>$. Acesso em: 20 dez. 2011,

AVENDAÑO, T. R. O desafio de retomar os mitos e reencantar o mundo a partir do Sumak Kawsay. IHU On-Line, ed. 340. São Leopoldo, p. 25-28, 2010. Disponível em: <http://www.ihuonline.unisinos.br/ index.php?option $=$ com_content $\&$ view $=$ article $\&$ id $=34$ 50\&secao=34 >. Acesso em: dez. 2012.

BRASIL. Ministério do Trabalho e Emprego. Secretaria Nacional de Economia Solidária. Disponível em: $<$ http://www.mte.gov.br/ecosolidaria/ecosolidaria_ oque.asp>. Acesso em: 10 set 2012.

CARTA de princípios da Economia Solidaria. Disponível em:<http://www.fbes.org.br/index2. php?option=com_content\&do_pdf=1\&id=63>. Acesso em: 17 set. 2013. 
CÉSPEDES, D. C. Hacia la reconstrucción del Vivir Bien. América Latina en movimiento, Equador, $\mathrm{n}$. 452, p. 8-13, feb. 2010.

CIRANDAS. Envolva-se para o bem-viver. Disponível em: <http://cirandas.net/envolvase>. Acesso em: 26 mar. 2013.

CONAES - CONFERÊNCIA NACIONAL DE ECONOMIA SOLIDARIA, 3., 2010, Brasília, DF. 'Pelo direito de produzir e viver em cooperação de maneira sustentável". Anais eletrônicos... Brasília: Conselho Nacional de Economia Solidaria, 2010. Disponivel em: <https://mail.google.com/mail/\#inbox/1487f4de98a04 c90? projector=1> Acesso em: 17 set. 2013.

FLIPO, F. Conceptual roots of degrowth. In: ECONOMIC DE-GROWTH FOR ECOLOGICAL SUSTAINABILITY AND SOCIAL EQUITY, p. 24-28, 2008, Paris. Anais... Paris, 2008.

FOLADORI, G. Limitantes do desenvolvimento sustentável. Tradução de Marise Manoel. Campinas: UNICAMP, 2001.

GAIGER. L. I. (Org.). Sentidos e experiências da economia solidária no Brasil. Porto Alegre: UFRGS, 2004.

GARCIA, E. Decrescimento e bem viver: algumas linhas para um debate adequado. In: LÉNA, P.; NASCIMENTO, E. P. do. (Org.). Enfrentando os limites do crescimento: sustentabilidade, decrescimento e prosperidade. Rio de Janeiro: Garamond, 2012.

KALLIS, G. In defence of degrowth. Ecological Economics. v. 70, p. 873-880, 2011.

LATOUCHE, S. Pequeno tratado do decrescimento sereno. Tradução de Cláudia Berliner. São Paulo: WMF Martins Fontes, 2009a.

La apuesta por eldecrecimiento: como salirdel imaginário dominante? Tradução de Patrícia Astorga. 2. ed. Icaria: Barcelona, 2009b.

Salir de la sociedade de consumo: voces y vias del decrescimento. Tradução de Magalí Sirera Manchado. Barcelona: Octaedro, 2012.

LEFF, E. Decrecimiento o desconstrución de economia: hacia um mundo sustentable. Revista Universidad Bolivariama, n. 21, p. 81-90, 2008.

LEÓN T. M. El 'buenvivir': objetivo y camino para otro modelo. 2010. Disponível em: <http://www.fedaeps. org/cambio-civilizatorio-y-buen-vivir/el-buen-vivirobjetivo-y-camino>. Acesso em: 10 jan. 2011.
MARTÍNEZ-ALIER, J. et al. Sustainable de-growth: Mapping the context, criticisms and future prospects of an emergent paradigm. Ecological Economics, v. 69 , p. 1741-1747, 2010.

MERICO, L. F. K. Introdução à economia ecológica. Blumenau: Edifurb, 2002.

MERINO, S. A desmistificação do desenvolvimento e as lições do Sumak Kawsay. IHU On-Line, São Leopoldo, 18 jan. 2013. Disponível em: <http://www. ihu.unisinos.br/noticias/517031-a-desmistificacaodo-desenvolvimento-e-as-licoes-do-sumak-kawsay>. Acesso em: 18 jan. 2013.

PENGUE, W. Fundamentos de economia ecológica. Buenos Aires: Kraicron, 2009.

RAUBER, I. Bolívia: uma opción civilizatória conrostro indígena. 2010. Disponível em: <http://isabelrauber. blogspot.com/2010/08/bolivia-una-opcion-civilizatoriacon.html>. Acesso em: 7 jan. 2011.

REGAZZONI, Q. A relação entre o Reino pregado por Jesus e o conceito de Vida Boa dos povos indígenas. IHU On-Line, São Leopoldo, p. 14-19, 23 ago. 2010.

SAAMAH, Abdallah et al. Final declaration. In: INTERNATIONAL CONFERENCE ON ECONOMIC DE-GROWTH FOR ECOLOGICAL SUSTAINABILITY AND SOCIAL EQUITY, p. 117-118, 2008, Paris. Anais... Paris, 2008.

SINGER, P. A Economia Solidária no Governo Federal. Mercado de Trabalho, n. 24, 2004. Disponível em: <http://www.mte.gov.br/ecosolidaria/ conf_textopaulsinger.pdf $>$. Acesso em: 10 abr. 2008.

VASCONCELLOS, M. A. S. Economia: micro e macro. São Paulo: Atlas, 2000. 